\title{
Channelling of controlled release formulation of ketoprofen (Oscorel) in patients with history of gastrointestinal problems
}

\author{
Hubert G Leufkens, John Urquhart, Bruno H Ch Stricker, Albert Bakker, Hans Petri
}

\begin{abstract}
Study objective-The aim was to determine if a new controlled release formulation (Oscorel) of the non-steroidal anti-inflammatory drug (NSAID) ketoprofen has been preferentially prescribed in patients with prior history of gastrointestinal disturbances.

Design-The study was a pharmacy records based comparison of the rates of prior prescribing of drugs indicated for peptic ulcer treatment in first recipients of Oscorel in 1989 versus recipients of other NSAID products.
\end{abstract}

Setting-A representative panel of Dutch community pharmacies serving approximately 425000 people was used.

Main results-Oscorel was launched in January 1989. Data on prescriptions dispensed in 1987-1988 to a total of 837 first users of Oscorel were analysed and compared with the dispensing history of a reference population including 30787 patients who did not receive a prescription for Oscorel during 1989. Compared to the reference population, first users of Oscorel included a greater proportion of females, of patients 75 years and older, of heavy users of NSAIDs, and of patients switching among different NSAIDS. A total of $24 \cdot 1 \%$ of first users of Oscorel had received peptic ulcer therapy in $1987-1988$, versus $15 \cdot 7 \%$ of the reference population. The rate ratio was 1.54 , with $95 \%$ confidence interval of $1.36-$ 1.74. Adjustment for stratifying variables caused only minor changes in the rate ratio, which remained stable on $1 \cdot 5$.

Conclusions-Oscorel appears to have been channelled into use in patients with recognised risk factors for gastrointestinal toxicity. This preferential prescribing probably resulted from expectations and claims that this product has a lower risk of such toxicity.

f Epidemiol Community Health 1992; 46: 428-432

There is an extensive history of controversy about the gastrointestinal toxicity of nonsteroidal antiinflammatory drugs (NSAIDs). ${ }^{12}$ Much of the controversy has been of a general nature regarding the NSAID class of drugs, but some has been product specific. ${ }^{1}$ One of the issues in product specific risk controversies is whether products are prescribed to patients with different background risks. For example, in the aftermath of the market withdrawal of the osmotic pump formulation of indomethacin (Osmosin, Indosmos) in 1983,
Inman's prescription event monitoring studies showed that previous recipients of Osmosin had a substantially higher background incidence of dyspepsia and gastritis than recipients of other NSAIDS studied at about the same time. ${ }^{34}$ Inman suggested that the promotion of Osmosin had fostered expectations that the product had a safety advantage with respect to gastrointestinal toxicity, thereby prompting its use in patients more prone to such toxicity. Indeed, selective prescription of newly introduced NSAIDs in persons with gastrointestinal complaints seems to be a feature of antirheumatic therapy. ${ }^{56}$ In general, in any class of drugs, a claimed safety advantage seems likely to prompt the prescribing of the product to patients known or suspected to be at risk to the condition at issue. Termed channelling, this is a general phenomenon, not limited to NSAIDs. ${ }^{7}$ It complicates the interpretation of adverse reports. In January, 1989, SmithKline and French introduced in The Netherlands a controlled release formulation (Oscorel, Oruvail) of the established NSAID, ketoprofen.

The product has been promoted with claims that it is a significant step forward in NSAID therapy, prompting the inference that it produces fewer gastrointestinal disturbances than other products in its class. ${ }^{8}$ Since its introduction, a total of 12 case reports of gastrointestinal bleeding and/or perforation in recipients of the product were reported to the Netherlands Centre for Monitoring of Adverse Reactions to Drugs (NARD). Between the introduction of ketoprofen in 1973 and the introduction of Oscorel in 1989, NARD received only two case reports of gastrointestinal bleeding or perforation related to non-Oscorel forms of ketoprofen. While it is well recognised that historical comparisons of numbers of adverse reaction reports are misleading, ${ }^{9}$ it is natural to question if this seeming change in reporting rate is a signal of increased risk of gastrointestinal toxicity due to the Oscorel form of ketoprofen. The present study was undertaken to determine if this form had been channelled into use in patients with prior history of gastrointestinal disturbances, and if so, to consider how such information might be interpreted.

\section{Methods}

PATIENTS AND DATA

Dutch pharmacy records enable a track to be kept of individual prescription drug use, due to the health insurance system which requires that patients virtually designate a single pharmacy from which they receive all prescription drugs. Drug use records include the name of the product, 
prescribed daily dose, quantity dispensed, start and stop date of therapy, identity codes for patient and prescriber, and the patient's age and gender. Computerised pharmacy records are the basis for reimbursement and thus provide a reliable and consistently formated source of information on patients' receipt of prescription drugs. Data on over the counter sales are incomplete due to the distribution by non-pharmacy outlets (drugstores, supermarkets). Patients' and prescribers' identities were unknown to those conducting this research.

Drug use data on NSAID recipients over a two year period (1987-1988) were collected from a representative panel of 36 pharmacies geographically dispersed throughout The Netherlands and serving approximately 425000 people. Data were collected by means of computerised data collection methods, resulting in a research database of more than one million prescriptions. Search of the pharmacy records revealed 65000 recipients of any NSAID during 1987-1988, together with records of all other drugs received by each of these patients. Of these, approximately 34000 patients had only received a single prescription for an NSAID during this period, making their consumption of NSAIDS ambiguous.

In the 36 pharmacies' records from the year 1989 , when Oscorel was introduced, all first users of Oscorel were identified. Oscorel recipients who had previously received NSAIDS were identified as "starters". Patients with more than one prescription for NSAIDs, but who did not receive Oscorel during 1989, were identified as the "reference" population. Starters were by definition switchers from other NSAIDs or, in case of previous use of non-Oscorel forms of ketoprofen, switchers of drug formulation. Except for information about which patients did start with Oscorel and which did not, no other drug use data during 1989 were available for this study.

\section{STUDY DESIGN}

We compared prescription drug histories of starters and of patients of the reference population, searching for antacids, $\mathrm{H}_{2}$ blockers, and other drugs indicated for use in peptic ulcer disease, such as sucralfate, bismuth chelate, and pirenzipine. Occurrence of a prescription for any drug among the foregoing designated the patient

Background data on Oscorel starters and reference population

\begin{tabular}{|c|c|c|c|}
\hline & Oscorel & Reference & $R R(95 \% C I)$ \\
\hline $\begin{array}{l}\text { Patients } \\
\text { Males } \\
\text { Females }\end{array}$ & $\begin{array}{lr}837 & (100 \cdot 0) \\
248 & (29 \cdot 6) \\
589 & (70 \cdot 4)\end{array}$ & $\begin{array}{ll}30787 & (100 \cdot 0) \\
12020 & (39.0) \\
18767 & (61.0)\end{array}$ & $\begin{array}{l}0.76(0.68-0.84) \\
1.15(1.10-1.21)\end{array}$ \\
\hline $\begin{array}{l}\text { Age group (years) } \\
0-44 \\
45-59 \\
60-74 \\
\geqslant 75\end{array}$ & $\begin{array}{ll}196 & (23.4) \\
223 & (26.6) \\
225 & (26.9) \\
193 & (23.1)\end{array}$ & $\begin{aligned} 11897 & (38.0) \\
7931 & (25.8) \\
6427 & (20.8) \\
4728 & (15.4)\end{aligned}$ & $\begin{array}{l}0.62(0.54-0.70) \\
1.03(0.92-1.16) \\
1.29(1.15-1.44) \\
1.50(1.32-1.70)\end{array}$ \\
\hline $\begin{array}{l}\text { Exposure group } \\
\text { Incidental users } \\
\text { Regular users } \\
\text { Heavy users }\end{array}$ & $\begin{array}{ll}333 & (39 \cdot 8) \\
347 & (41 \cdot 4) \\
157 & (18 \cdot 8)\end{array}$ & $\begin{aligned} 15139 & (49 \cdot 2) \\
12013 & (39.0) \\
3635 & (11 \cdot 8)\end{aligned}$ & $\begin{array}{l}0.81(0.74-0.88) \\
1.06(0.98-1.15) \\
1.59(1.38-1.84)\end{array}$ \\
\hline $\begin{array}{l}\text { Switch groupt } \\
0 \text { switch } \\
1 \text { switch } \\
>1 \text { switch } \\
\end{array}$ & $\begin{array}{ll}404 & (48 \cdot 3) \\
164 & (19 \cdot 6) \\
269 & (32 \cdot 1) \\
\end{array}$ & $\begin{aligned} & 14303(46.5) \\
& 10341(33.6) \\
& 6143(19.9) \\
&\end{aligned}$ & $\begin{array}{l}1.04(0.97-1.12) \\
0.58(0.51-0.67) \\
1.61(1.46-1.78)\end{array}$ \\
\hline
\end{tabular}

as a peptic ulcer therapy recipient for the purposes of this study. We also compiled information on levels of exposure to NSAIDs, switching among individual NSAIDs, age, and gender. NSAID users were classified depending on duration of exposure to NSAIDS, in terms of number of days' drug supply, as "incidental" (0-30 days), "regular" (31-180 days), or "heavy" (>180 days). NSAID users were also classified depending on the number of times during the period 1987-1988 that they were prescribed a different NSAID: 0 switches if they always received the same NSAID, 1 switch if they received two different NSAIDS, and $>1$ switch if they received $>2$ NSAIDs.

We conducted a separate analysis by comparing the prior drug use histories of starters and the subset of the reference population who used ketoprofen in the form of Orudis. Both competing products contain ketoprofen and are controlled release formulations. Therefore patients on Orudis should provide pertinent information for comparison.

\section{STATISTICAL ANALYSIS}

The null hypothesis of the study was that the proportion of peptic ulcer therapy recipients (PUTR) among starters was no different than among the reference population. Statistical analysis consisted of calculation of the ratio of the proportion of PUTR in starters versus that in the reference population. Significance of the rate ratios (RR) was determined by the test based 95\% confidence intervals. ${ }^{10}$ Mantel-Haenszel weighting was used for stratified analysis. Categorical variables were evaluated by $\chi^{2}$ statistics. All analyses were carried out using the SAS statistics package. ${ }^{11}$

\section{Results}

Among the 36 pharmacies, a total of 1802 first users of Oscorel in 1989 were identified, 860 $(47.7 \%)$ of whom had a prior history of NSAID use during 1987-88, thus qualifying them as starters. Twenty three of the 860 starters $(2 \cdot 7 \%)$ had to be deleted because of missing or incomplete data regarding their drug histories. Thus 837 starters were analysed. The reference population of patients who received more than one prescription for NSAIDs during 1987-1988 and who did not receive a prescription for Oscorel during 1989 numbered 30787 patients.

Oscorel was launched in January 1989, but it took until the third quarter before physicians began substantially prescribing the product. Rapid growth in prescribing occurred during the third and fourth quarters. A fifth of the physicians in the areas served by the 36 pharmacies accounted for half of the recipients of Oscorel. Analysis of previous use of individual NSAIDs by starters showed that diclofenac was used most commonly in 1987-1988, followed by naproxen, ibuprofen, indomethacin, and piroxicam. Ketoprofen was used in $6.2 \%$ of starters and in $2.5 \%$ of the reference group.

The table summarises pertinent data on starters and on the reference population. Compared to the reference population, starters included a somewhat greater proportion of females. Patients 75 years and older showed up more in Oscorel 
starters when compared with the reference population $(R R=1 \cdot 50 ; 95 \%$ CI 1.32-1.70). Starters had a background of more "heavy" use of NSAIDS and switching among different NSAIDs. Among starters, $16.9 \%$ were exposed for longer than 180 days to NSAIDs. In the reference population $11.5 \%$ of patients were "heavy" users ( $R R=1.59 ; 95 \%$ CI 1.38-1.84). The proportion of non-switchers was similar in starters and in the reference population. However, starters appeared to have a background of higher rates of intensive switching among individual NSAIDs. Among starters, $32 \cdot 1 \%$ of patients switched in 1987-1988 to more than two different NSAIDs. The background rate was $19.9 \%(R R=1.61 ; 95 \%$ CI $1.46-1 \cdot 78)$.

A total of $24 \cdot 1 \%$ of starters had received peptic ulcer therapy in $1987-1988$, versus $15.7 \%$ of the reference population. The rate ratio was 1.54 , with $95 \%$ confidence intervals of $1 \cdot 36-1 \cdot 74$. The figure shows the proportions of peptic ulcer therapy recipients among starters and the reference population, stratified in various ways. The data demonstrate consistency in higher incidence of recipients among Oscorel starters than among the reference population, with heavy NSAID users and younger patients being the exceptions. Adjustment for stratifying variables caused only minor changes in $R R$ which remained stable on 1.5 .

A possible source of confounding could be the prescribing behaviour of physicians who adopted Oscorel. Early adopters of new drugs may also tend to prescribe them frequently to patients with complicated histories, eg, peptic ulcer therapy recipients. We evaluated this by restricting the reference group to only those patients who were under the same physicians as Oscorel starters $(n=23465)$. Among this alternative reference group an incidence of peptic ulcer therapy recipients of $15.4 \%$ was found, indicating no difference from the total reference group. We looked in detail at the prescribing patterns of the $20 \%$ of the physicians who accounted for half of the recipients of Oscorel. There was no significant difference in the number of prescriptions for peptic ulcer therapy per 1000 patient days of NSAID use issued by these physicians, versus by other physicians.

We identified 771 patients who used nonOscorel forms of ketoprofen in the observation period and who were not starters. In $16.6 \%$ of these patients a history of peptic ulcer therapy was found, a rate which was comparable with the baseline level in the reference group $(R R=1.06$; 95\% CI 0.90-1.24). Likewise, stratified analysis did not show any significant differences in rates of peptic ulcer therapy in Orudis users when compared with the reference group. Thus there was no evidence to suggest that the drug ketoprofen was selectively overprescribed or underprescribed to peptic ulcer therapy recipients, notwithstanding published evidence that the drug has a better gastrointestinal tolerance than indomethacin. $^{12}$

It was a conservative manoeuvre to exclude from the analysis the 30000 one time recipients of an NSAID prescription during 1987-1988. When these patients' data were kept in the analysis, the rate ratio was $1 \cdot 7$, not $1 \cdot 5$. Thus the exclusion did not change the interpretation of the study.

\section{Discussion}

The results of our study show consistency in preferential prescribing of the newly introduced ketoprofen formulation Oscorel in patients with a history of peptic ulcer therapy. Thus Oscorel appears to have been channelled into use in patients with recognised risk factors for
Proportions of peptic ulcer therapy users among starters of Oscorel and the reference population stratified for gender $(A)$, age $(B)$, switching $(C)$, and duration of exposure to NSAIDS (D)
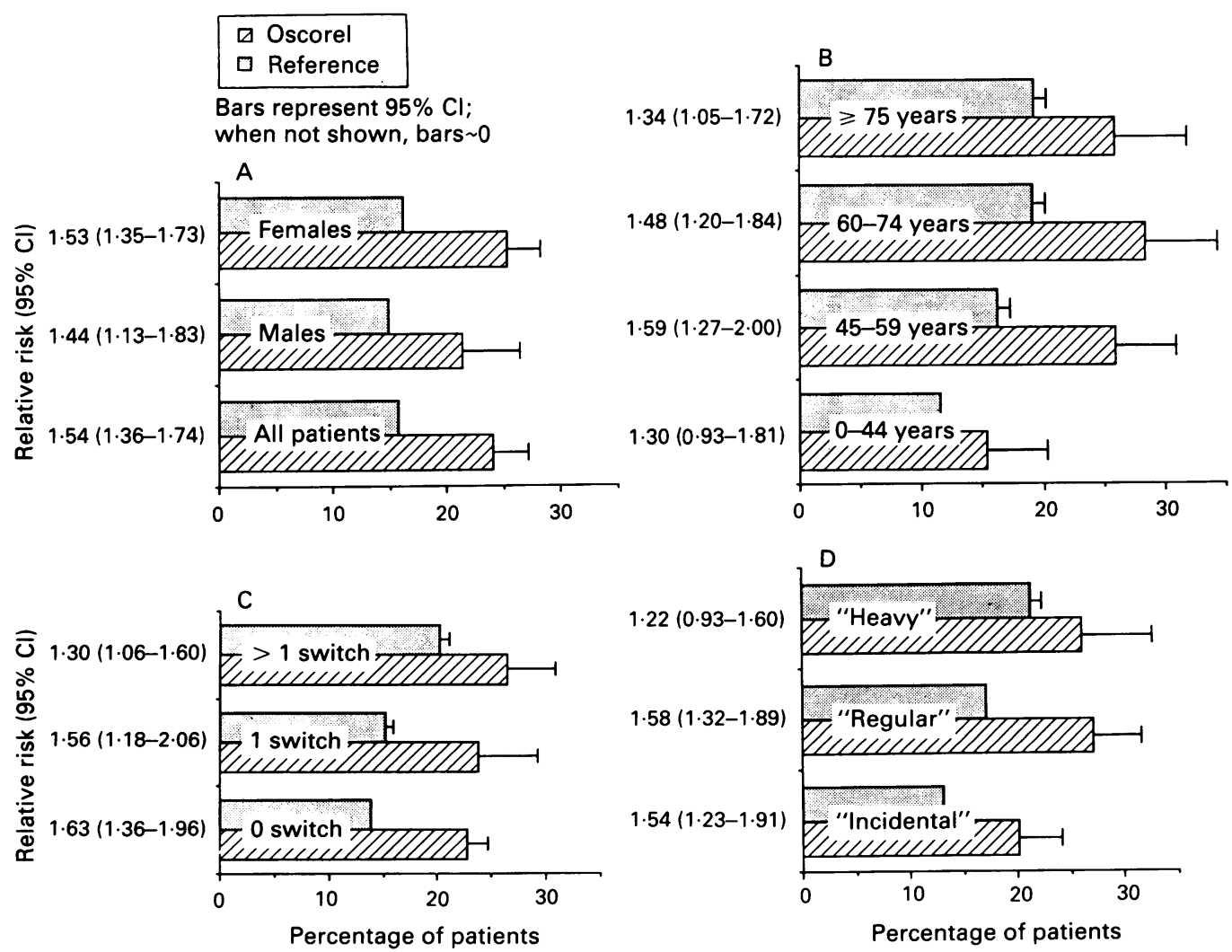
gastrointestinal toxicity. Channelling probably resulted from expectations that Oscorel has a lower risk of gastrointestinal toxicity.

New NSAID products are claimed to be less liable to adverse gastrointestinal effects, which are the most common of the side effects of this class of drug. It is not surprising, as Epstein et al have noted, that physicians might tend to try new agents or new formulations of old NSAIDs. ${ }^{13}$ For example, sulindac was introduced with high expectations for reduced renal side effects, but was later found to have the highest rate of upper gastrointestinal bleeding. ${ }^{5}$ Avila et al found in the Group Health Cooperative database that two NSAIDS newly launched in 1982 (piroxicam and sulindac) were prescribed preferentially among cimetidine users. ${ }^{6}$ The predictive value of the use of antacids and $\mathrm{H}_{2}$ blockers of hospital admissions for perforated peptic ulcer was confirmed by the same research group and recently included in class labelling by the US Food and Drug Administration. ${ }^{14} 15$

The descriptive nature of this study determines the limitations of the selection of a "like with like" reference population. However, stratified analyses demonstrated consistency of higher rates of peptic ulcer therapy in starters, independently of characteristics of subsets in Oscorel starters and reference population. The comparison in this study was conducted retrospectively with data drawn from pharmacy records. We made the assumption that due to a strong liaison between patient and pharmacy, identification of users of Oscorel in 1990 provided pertinent information on starters as well as on the reference population. Patients who moved away, died, or changed pharmacy could not be identified. However, there is no indication that starters and patients from the reference population differed with respect to this. Incidental users represented approximately half the recipients of NSAIDs, as judged by data collected during a two year interval. If the interval was longer, it would probably have included some incidental users with intervals between NSAID prescriptions of more than two years. Thus some of the Oscorel recipients classed as first time NSAID recipients could have been classed as starters had we used a longer time period in which to define the reference population. We cannot, however, identify any reason why a longer period for defining the reference population would have changed the main results of the study.

The introduction of Oscorel seems to have features that resemble the introduction of Osmosin. In both cases, while the drug substance was familiar, the technical aspects of the new dosage form attracted attention and generated optimism and claims of a safety advantage. It is a matter of speculation in both situations as to the extent to which the reporting rate of adverse reactions was increased by disappointment at the occurrence of the usual types of NSAID toxicity. A major concern with respect to the introduction of new drugs is that physicians might adopt these agents too soon in such a way that proper monitoring and evaluation of outcomes are threatened. Inman has recently called attention to the potential problems in postmarketing surveillance created by the fact that a tiny fraction of physicians sometimes account for a disproportionate fraction of patients prescribed new products. ${ }^{3} \mathrm{He}$ discovered that many physicians responsible for the $30 \%$ non-response in the Prescription Event Monitoring scheme prescribed to far more patients than could possibly be monitored. ${ }^{16}$ Analysis of the introduction of three heavily promoted new drugs revealed that a very small proportion of physicians $(0.5 \%)$ had issued prescriptions to between $50-200$ patients, accounting for $11 \%$ of sales. There is no evidence that this kind of overprescribing figured prominently in the marketing of Oscorel. Classical diffusion of innovation teaches that early market adoption of new products occurs among $20-40 \%$ of potential product adopters, which is in accordance with the data for Oscorel. ${ }^{17}$

A number of case histories with NSAID have provided evidence that the first two years after introduction are the most risky, with a peak in adverse drug reaction reporting two years after marketing. ${ }^{18} 19$ The surge of reports associated with the use of Oscorel might partly be the result of "novelty breeds suspicion". However, the introduction of non-Oscorel forms of ketoprofen on the Dutch market did not yield more than two reports of serious gastrointestinal complications since 1973. This brings us to the point that reporting trends with respect to NSAIDs have changed in recent years, due to the alarming effect of a number of withdrawal cases (Indosmos, Opren). In 1985, comparison of newly introduced piroxicam with other individual NSAIDs indicated that piroxicam had higher rates of adverse drug reaction reports. A consumer group in the USA had petitioned for a ban on the use of piroxicam in the elderly. Detailed analyses of secular reporting trends, differences in users populations, and prescribing patterns conducted by the Food and Drug Administration and the manufacturer have led to the conclusion that piroxicam is neither more nor less dangerous than other NSAIDs. ${ }^{20} \mathrm{An}$ important lesson that can be learned from piroxicam is how careful comparisons should be made among individual products of NSAID. The results of our study emphasise the need for great prudence in evaluating adverse drug reactions reports. A deficit in proper ascertainment of patients' actual drug use is probably an important explanation why data on NSAID associated gastrotoxicity are so conflicting. ${ }^{21}$

\section{CONCLUSIONS}

In conclusion, our data provide evidence for rejecting the null hypothesis that starters and non-starters of Oscorel were similar with respect to their background of NSAID use and peptic ulcer therapy. We looked for channelling. It is there. It can reasonably account for a $30-50 \%$ excess in case reports, as the channelling resulted in half again more patients with a history of previous upper gastrointestinal problems, and thus at presumably higher risk of such problems during their use of Oscorel. If Oscorel has any risk differential, in either direction, it will have to be assessed on other grounds than raw counts of adverse reaction reports.

The authors are much indebted to the pharmacists who provided the utilisation data. Pharmacom generously supported the study with technical and project management assistance. The discussions with Ron M. Herings 
were very helpful. Caroline $\mathbf{B}$ Ameling and Eibert $\mathbf{R}$ Heerdink provided excellent computer and data management support.

1 Urquhart J. Two cheers for NSAIDs. Gut 1986; 27 1287-91.

2 Hawkey CJ. Non-steroidal anti-inflammatory drugs and peptic ulcers. BMF 1990; 300: 278-84.

Inman B. Comparative study of five NSAIDS. PEM New 1985; 3: 3-13.

4 Burley D, Inman WHW, eds. Therapeutic risk. Chichester: John Wiley and Sons, 1988.

5 Carson JL, Strom BL, Morse L, et al. The relative gastrointestinal toxicity of nonsteroidal antiinflammatory drugs. Arch Intern Med 1987; 147: 1054-9.

6 Avila MH, Walker AM, Romieu I, Perera DR, Spiegelman DL, Jick H. Choice of nonsteroidal antiinflammatory drug in persons treated for dyspepsia. Lancet 1988; ii: 556-9.

7 Urquhart J. ADR crisis management. Scrip 1989; 1388 : 19-21.

8 SmithKline and French. Promotional publications: Oscorel 1989.

9 Center for Drugs and Biologics, US Food and Drug Administration. Recommendation in piroxicam imminen hazard proceeding. May 14, 1986. In: FDA's recommendation regarding disposition of Imminent Hazard Petition regarding Feldene (piroxicam)-Decision. May 27, 1986 regarding Feldene (piroxicam - Decision. May 27, 1986 Secretary of Health and Human Services.

10 Rothman KJ. Modern epidemiology. Boston: Little, Brown and $\mathrm{Co}, 1986$.
11 Anonymous. $S A S / S T A T$ guide for personal computers. Cary SAS Institute, 1985

12 Fossgreen J, Kirchheiner B, Petersen FO, Tophøj E, Zachariae E. Clinical evaluation of ketoprofen in rheumatoid arthritis. Scand $\mathcal{F}$ Rheumatol 1976; 14: 93 8 .

13 Epstein AM Read JL, Winickhof R. Physician beliefs, attitudes, and prescribing behavior for antiinflammatory attitudes, and prescribing behavior for antinflammatory

Jick SS, Perera DR, Walker AM, Jick H. Nonsteroidal antiinflammatory drugs and hospital admission for

perforated peptic ulcer. Lancet 1987, ii: 380-2.

Anonymous. Physicians desk reference. Oradell (NJ): Medical Economics Co, 1990: 1626-8.

16 Inman WHW. Black triangles and promotional PMS. PEM News 1988; 5: 20-7.

17 Rogers EM. Diffusion of innovations: an overview. In Roberts EB, Levy RI, et al, eds. Biomedical innovation. Cambridge: MIT Press, 1981: 75-97.

18 Weber JPC. Epidemiology of adverse reactions to nonsteroidal antiinflammatory drugs. Adv Inflammation Res 1984; 6: 1-7.

19 Sachs RM, Dieck GS. The Feldene experience: a case study In: Horisberger B, Dinkel R, eds. The perceptions and Afrug safety risks. Berlin: Springer Verlag, 1989: 81-9.

20 Rossi AC, Hsu JP, Faich GA. Ulcerogenicity of piroxicam an analysis of spontaneously reported data. $B M \mathcal{F} 1987 ; 294$ : 147-50.

21 Strom BL, Taragin MI, Carson JL. Gastrointestinal bleeding from the nonsteroidal antiinflammatory drugs. Agents Actions 1990; 29: 27-38. 